\title{
Educação de surdos em tempos de inclusão
}

Ana Dorziat*

\section{Resumo}

A educação de surdos sempre foi tomada de forma técnica. Desde a época da visão oralista até os dias atuais, quando a língua de sinais é aceita nos diferentes ambientes, há uma simplificação de conceitos sobre o tema, contribuindo para a permanência de práticas educativas colonialistas. A partir dessa constatação, elaboramos o presente texto com foco na Língua de Sinais, trazendo algumas situaçóes observadas em escolas inclusivas, com o objetivo de desocultar as intençôes subliminares à inclusão na política e prática educacional, as quais criam expectativas de uma escola ideal sem por em questáo a escola real, que, por estar a serviço do mercado, inaugura novos mecanismos de exclusão e discriminaçáa sob o discurso da igualdade e da tolerância.

Palavras-chave: Surdos; Educação; Língua de Sinais; Inclusão/Exclusão.

* Professora doutora da Universidade Federal da Paraíba, João Pessoa, Paraíba, Brasil. 


\section{Deaf education in inclusion times}

\section{Abstract}

The education of the deaf has always been treated in a technical form. Since oral vision until the present day, when the the sign language is more accepted in different environments, there is a simplification of concepts about the theme, contributing to the permanence of colonial educational practices. From this observation, we elaborate the present text with a focus on sign language, bringing some situations observed through a report of some events seen inside the schools, which claim they include all children, aiming to reveal the inclusion's intentions, in the educational policy and practice, which create expectations of an ideal school without considering the real school that is working on behalf of the economy developing, new methods of exclusion and discrimination, making use of the speech of equality and tolerance.

Keywords: Deaf; Education; Sign Language; Inclusion/Exclusion.

\section{Considerações iniciais: a educação de surdos e o contexto da globalização}

A educação de surdos é marcada por uma história de equívocos. Os surdos, na sua trajetória educacional, não foram considerados, como afirma Sacks (1990), pessoas pertencentes a uma entidade linguística e cultural própria, pelo fato de não ouvirem o suficiente para processar informaçôes linguísticas pela via de acesso oral -auditiva. Os procedimentos educacionais criados para eles tratavam-nos como seres incompletos, deficientes, que necessitavam se apropriar da língua majoritária, além de negar-lhe o direito de usar sua língua natural, a Língua de Sinais. Essas práticas, na verdade, faziam parte da visão educacional hegemônica sobre desenvolvimento humano, muito presente em uma educação de teor tecnicista.

Os estudos em várias áreas (linguística, sociologia, educação, etc.), mostrando os transtornos que causam a ausência de uma linguagem natural na constituição humana e a importância da interação dos sujeitos com o meio, fizeram emergir outras visões de educação que, embora mantivessem ainda uma tradição muito voltada para o desenvolvimento psicológico humano universal, deram sua parcela de contribuição para que se repensasse a educação de surdos. Surgem, então, novas concepçóes de desenvolvimento do trabalho educacional com surdos, valorizando a comunicação através da linguagem gestual. Entre elas, fortalece-se os princípios do Bilinguismo, que propõem o domínio de duas línguas: a Língua de Sinais, como primeira língua, e a Língua Portuguesa, na sua modalidade oral/escrita, como segunda língua.

Embora o aspecto linguístico seja central nessa abordagem, é necessário o inserirmos numa perspectiva mais ampla, considerando a problemática educacional, de fundo político-curricular. Portanto, agregada à valorização da Língua de Sinais, urge desarticular visóes cristalizadas de desenvolvimento humano único no âmbito pedagógico e considerar os diferentes modos de elaboração e expressão como poten- 
cialidades per se. Nesse sentido, e educação de surdos deve compor um sistema que atenda ao princípio de uma educação culturalmente engajada e que desconstrua visóes homogêneas e estáticas, entendendo a subjetividade na perspectiva da alteridade.

Portanto, reivindicar educação para os surdos significa muito mais que a simples adaptação ao tipo de educação existente nas escolas, trazendo a Língua de Sinais para o processo. Representa, além de ter como critério a valorização da Língua de Sinais, questionar as generalizaçóes que fundamentam o ensino nos ambientes escolares, desconsiderando as diferenças, nas suas várias nuances. Essa visáo parte de estudos que vêm problematizando os currículos oficiais, engessados e fixos, e denunciando os efeitos devastadores nos últimos cem anos, quando foram estabelecidas práticas colonialistas na educação. Em relação ao ensino de surdos, essas práticas são chamadas também "ouvintistas", pois adotam mecanismos próprios para os ouvintes dentro dos currículos (SKLIAR, 1997).

$\mathrm{Na}$ verdade, o ouvintismo é também uma variável a ser problematizada, uma vez que a educação voltada para os ouvintes é questionável. Ou seja: a que ouvinte a educação está atendendo? Todos os ouvintes têm visto seus direitos serem atendidos no sistema escolar? Definitivamente, entendemos que não. Ao não estabelecer, de maneira firme e clara, as relaçôes entre por que fazer, para que fazer, para quem fazer e como fazer (DORZIAT, 1999), a escola continua, através da escolha de conteúdos e de práticas pedagógicas específicas, a serviço de uma ideologia dominante, uma vez que não existe um fazer pedagógico neutro e que se adapte a toda e qualquer situação escolar.

Nesse contexto de discussão, as questôes aqui problematizadas dizem respeito ao interior dos sistemas educacionais, quaisquer que sejam a sua modalidade: especial ou regular. Consideramos que tanto as escolas de surdos quanto as de ouvintes mantém estruturas rígidas e padronizadas e, por isso, precisam ser abaladas, mesmo que tenham como língua de instrução a Língua de Sinais.

No entanto, em tempos de inclusão, quando é muito comum a escolarização de surdos nos sistemas regulares, não podemos deixar de nos sentir provocados a levantar algumas consideraçóes. Embora essa iniciativa tenha gerado posturas de defesa incondicional entre vários estudiosos na área, porque vai ao encontro dos anseios dos que lutam historicamente por uma sociedade sem barreiras, includente, entendemos que essa defesa deve estar radicalmente fundamentada, sob o risco de cairmos nas armadilhas de um sistema que usa como instrumento discursos progressistas, para implementar práticas individualistas, competitivas e meritocráticas, instituindo novas estratégias de exclusão.

Por isso, o direito de todos e, no seu ínterim, as particularidades das práticas educacionais voltadas aos surdos devem estar atrelados ao desnudamento e à problematização das questôes subliminares que os determinam, o que significa olhar a inclusão no seu sentido político e social. Isso requer uma análise profunda sobre a contemporaneidade e os processos de globalização que, como todo processo com fundo altamente ideológico, possui relação profunda entre a esfera econômica e as 
demais esferas da vida social (política, cultural, religiosa, jurídica), mesmo existindo uma forte tendência de os debates acerca da globalizaçáo reduzirem-na à esfera econômica (BAUMANN, 1996). Essa tentativa de descolamento nada mais é do que o encobrimento da rede de poder e interesses que envolvem o processo. Longe de ser consensual, a globalização é um vasto e intenso campo de conflitos entre grupos sociais, Estados e interesses hegemônicos, por um lado, e grupos sociais, Estados e interesses subalternos, por outro.

Através de mecanismos poderosos, a globalização hegemônica marca ideologicamente, instituindo os modos de convivência e de disseminação de valores próprios de uma sociedade fundamentalmente mercantil. Ela age nos processos de trabalho, decorrentes do paradigma tecnológico, determinando mudanças nas competências requeridas da força de trabalho, nos conhecimentos necessários para operar os sistemas produtivos e na maneira de aquisição dessas competências e conhecimentos.

Nesse contexto, é exigido das pessoas capacidade de aprendizado e de resolução de problemas, flexibilidade e versatilidade para realizar tarefas em constante processo de modificação. São valorizadas, também, a iniciativa pessoal, a capacidade de trabalhar em grupo, a capacidade de comunicação oral e escrita. Os processos de automação industrial, por sua vez, requerem capacidades específicas e habilidades, além de uma visão geral do processo produtivo e de noçóes de gestáo da produção. A oferta desses atributos torna-se indispensável para desenvolver e manter os investimentos, exigindo dos trabalhadores uma sólida educação geral.

De modo a propiciar as condiçôes de desenvolvimento das capacidades e dos conhecimentos básicos para as novas exigências do mercado, a recomendação das agências financiadoras mundiais é a universalização do ensino fundamental e a elevação dos padróes de ensino. A educação apresenta-se, assim, como uma condição básica para o desenvolvimento humano que incide na qualidade da força de trabalho, variável estritamente associada ao nível de educação formal da população, que, por sua vez, está fortemente relacionado ao nível de renda da população: as populaçóes menos escolarizadas estão numa faixa de renda inferior à daquelas mais escolarizadas. Com isso, a globalização tende a gerar novas desigualdades, além de fazer recrudescer as já existentes, sobretudo nos países menos desenvolvidos, onde existe a difusão desigual de inovaçôes tecnológicas, o surgimento de ilhas de excelência que convivem com bolsóes de miséria, o aumento da distância entre os participantes e os excluídos do processo. Para Castells (1995, p. 20), "o que caracteriza a globalização é que ela é extraordinariamente excludente e inclusiva ao mesmo tempo. Inclui o que gera valor e exclui o que não é dinâmico e não cria valor".

O mais perverso nessa nova era globalizadora é sua influência mercantilista nas elaboraçôes educativas, sobretudo em suas práticas pedagógicas. São utilizadas estratégias subliminares, que se apropriam do discurso de valorização das diferenças e do interesse pelas culturas locais, mas mantém as regras do mercado, que se baseiam na competição, individualismo e padronização. Mas, nem mesmo os esforços, no sentido de criar meios para a homogeneidade de pensamentos, atitudes e valores, são alcançados, intensificando ainda mais os problemas educacionais, uma vez que 
a população escolar, em sua heterogeneidade crescente, não se enxerga e, assim, não consegue se apropriar dos conhecimentos adequadamente. Isso se dá porque não é considerado o fato de que a lógica global termina passando por um processo de adequação às lógicas locais, denotando uma trajetória que não é uniforme na sua essência. Ao contrário, é complexa, contraditória e conflituosa.

É nesse contexto ambíguo que se coloca o discurso da inclusão: ao mesmo tempo em que constitui apelo a uma educação democrática e cidadã confunde-se a intençôes menos elevadas, que compõem o quadro da política globalizadora hegemônica, atrelada a interesses mercadológicos e, para se manter, produz resultados que confirmem a lógica desses sistemas.

A partir dessa realidade, o foco na inclusão de surdos exige uma reflexão rigorosa que envolve o particular e o geral, como produto de diferentes pensares, diferentes percepçôes de mundo e de experiências. Isso é possível através dos fundamentos científicos presentes na teoria dos Estudos Culturais, que considera as diferenças no currículo como uma atitude de atenção, de coragem e, sobretudo, de criação (CORAZZA, 2004). Pensando nessa direção, Corazza (2004, p. 184) afirma que se faz necessário modificar a formação do intelectual da Educação,

constituindo-o menos como pedagogo, e mais como analista das culturas, como um artista, como um poeta que se (re)inventa permanentemente, que já tem condições de pensar e bailar com seus conhecimentos para educar uma infância des-iludida.

Essa reflexão tem como fio condutor as noções de cultura que se contrapõem a visão de que a realidade social seria como uma árvore, com troncos e ramos, que se dividem de forma binária, sem estabelecerem conexôes entre eles. Podemos buscar inspiração nas concepções de Deleuze e Guattari (1976), que vêem pessoa/cultura como entidades múltiplas, com entrecruzamento em todas as ramificações, que envolvem organizações de poder, lutas sociais, arte, linguística, educação... Portanto, os fenômenos sociais e/ou comportamentais podem ser considerados por vários ângulos. Mais do que analisá-los em si, é preciso nos perguntarmos por que em determinado contexto ele se construiu, se manteve ou foi posto em causa.

Nesse contexto, falar de cultura é tratar de escolhas individuais que são feitas ao longo de todo um ciclo de vida humana, mas que, ao contrário de visóes tradicionais, deve ser vista na sua plasticidade e dinamicidade, por ser algo contextual e contextualizante. Haja vista ser a cultura uma aprendizagem de valores e de normas obtidas a partir das dinâmicas de socialização, Forquin (1993) propõe o uso do termo culturas (no plural).

Embora a instituição Escola, pressionada em todo o mundo, tendo em vista as novas configuraçóes de sua população-alvo, tenha passado a tratar, em termos formais, a diversidade cultural e o acesso de todos ao ensino, sua forte tradição reguladora administrativa de ritmo e modo de trabalho tem levado a uma descontinuidade entre a cultura escolar e as diferentes culturas que a frequentam, o que representa um conflito que pode produzir dois tipos de exclusão: a mascarada, aquela que mantém 
os alunos na escola, mas os desconsidera de uma participação real na construção de conhecimentos; e a física, que representa a saída definitiva do sistema educativo.

Quando se trata da educação de surdos, é comum a inclusão estar relacionada ao uso da língua de sinais, seja na sala de recursos multifuncionais, com um instrutor surdo, seja na sala de aula, com o intérprete de língua de sinais. Mais do que um aspecto linguístico-cultural, a adoção da Língua de Sinais se constitui um artefato metodológico, um apêndice ao tipo de educaçáo já existente. Com isso, limita-se as possibilidades bilíngues dos surdos e desconsidera-se a necessidade de reconhecimento político da surdez enquanto diferença, como defende Skliar (1997).

A Língua de Sinais deve ser entendida como muito mais que um código comunicativo, tendo em vista sua importância na constituição dos surdos. Quando insistimos em trazer à discussão à totalidade do fenômeno educativo, não estamos a diminuir a importância da Língua de Sinais, como aspecto primordial à educaçáo dos surdos. Ao contrário, reconhecemos que as potencialidades da diferença surda são intrínsecas ao desempenho dessas pessoas na aquisição de uma língua cujo canal de comunicaçáo é o viso-gestual e, também, na sua habilidade linguística que se manifesta na criação, uso e desenvolvimento dessa língua em relação com o mundo que os rodeia.

Se pensarmos os anos iniciais de escolaridade como um momento em que as crianças devem se relacionar com os conhecimentos com interatividade e ludicidade, de modo a captar o sentido presente nos diversos aspectos da natureza humana e suas inter-relaçóes, podemos dimensionar o valor de um sistema linguístico adequado de apreensão e externalização de informaçóes, conhecimentos, relaçóes enfim.

Portanto, embasadas em estudo que teve por objetivo analisar a relação entre o fazer pedagógico de salas de aula de anos iniciais, que possuam estudantes surdos, com os processos curriculares e sociais mais amplos, desenvolvemos o presente artigo.

\section{Metodologia: a pesquisa}

O estudo foi realizado em uma escola da rede pública regular de ensino fundamental, localizada na cidade de Joáo Pessoa/PB, onde existia um número considerável de surdos incluídos, especificamente em turmas de $3^{\circ}$ e $4^{\circ}$ anos do Ensino Fundamental. $\mathrm{O} 3^{\circ}$ ano era composto por 27 alunos ouvintes e uma aluna surda e o $4^{\circ}$ ano era composto por 21 alunos ouvintes e um aluno surdo.

Visando levantar os procedimentos pedagógicos utilizados no desenvolvimento curricular, foram planejados momentos de observaçóes de situaçóes educacionais em sala de aula, as quais foram escolhidas de forma aleatória. Essas observaçóes foram realizadas de forma reservada, com registros em diários de campo e, sempre que possível, acrescida de conversas informais em momentos extra-classe.

Para a realização das observaçóes, foi de fundamental importância o estudo bibliográfico prévio sobre o tema, o que proporcionou uma melhor apreensão da noção e a dimensão exata do que queríamos levantar e o como observar, planejando um caminho, uma linha de ação, como esclarece Lüdke e André (2005). 
O produto das observaçóes realizadas em sala de aula foi organizado em forma de Situaçôes. Selecionamos algumas delas para desenvolver reflexóes sobre os aspectos presentes na contemporaneidade: a língua de sinais, os ideais de inclusáo e a globalização.

\section{Reflexões: o contexto escolar e as perspectivas subjacentes}

As situaçóes, apresentadas a seguir, ilustram como tem se dado a participação dos surdos nas escolas em diferentes contextos, quanto à turma, assunto, professores e estudantes. Para melhor visualização, optamos por colocar em destaque (negrito) aspectos considerados importantes vieses analíticos.

\section{Situaçáo 1}

Aula de Matemática: assunto - "Divisibilidade"

A professora explicava as regras da divisibilidade e em nenhum momento se dirigiu ao surdo. Não havia interpretação simultânea. Após a explicação, a professora passou exercícios e, enquanto ela copiava no quadro, o intérprete continuava explicando o conteúdo para o estudante surdo. O intérprete levava a dúvida do surdo à professora, mas não incentivava o aluno a se dirigir a mesma. Esta permanecia sentada, explicando ao intérprete, que retornava e explicava ao surdo. A professora perguntava ao intérprete se o surdo tinha entendido e não ao próprio aluno. $\mathrm{O}$ surdo não se dirigia à professora e sim ao intérprete. A professora corrigiu o exercício sem se dirigir ao surdo. Ele ainda escrevia, enquanto a professora explicava oralmente cada questáo do exercício, sem se voltar em momento algum a ele. Os alunos ouvintes respondiam oralmente as questóes e o surdo ainda copiava o exercício.

\section{Situaçáo 2}

\section{Aula de Português: atividade de leitura e interpretaçâo}

A professora sempre se referia ao surdo através da intérprete. Pareceu demonstrar interesse por ele, quando antes de iniciar a explicação, saiu em busca da intérprete. Depois de a intérprete se ausentar novamente, após ter interpretado a explicação dada pela professora, o surdo questionou algo. A professora tirou a dúvida surgida, sem participaçáo da intérprete, porém não utilizou Libras, não sendo possível a compreensão por parte do aluno. $\mathrm{Na}$ ausência da intérprete, a professora estava sempre se dirigindo ao surdo, para observar suas tarefas. Com a volta da intérprete, a professora sentou-se distante do surdo. A intérprete sentou-se junto ao surdo e começou a explicar o exercício, enquanto a professora já não explicava mais. Esse surdo era muito tímido e retraído, pouco interagia com os outros alunos. Estabelecia contato apenas para pedir uma borracha, apontador. A intérprete se ausentou novamente para dar espaço a uma instrutora, que ensinava 
sinais a todos os alunos desta turma. A professora náo participou da aula de sinais. O surdo também náo. Segundo a professora, durante uma conversa com a intérprete, o surdo quase não sinalizava, é como se não soubesse a Libras. A professora também ressalvou: sabendo o alfabeto, eles constroem as palavras com mais facilidade. Durante o tempo de observação deste dia, o surdo só sinalizou a palavra "pronto".

\section{Situação 3}

\section{Aula de Ciências: assunto - "Órgão Reprodutor Feminino"}

Após escrever todo o conteúdo da aula no quadro, a professora iniciou a explicação. Ela se voltava plenamente aos ouvintes. Explicava, enquanto os surdos ainda estavam escrevendo. Após os surdos terminarem de copiar, o intérprete iniciou a explicaçáo que era, na verdade, resumo do que a professora havia dito. A professora continuava a dar normalmente sua aula e, devido à presença do intérprete, não questionava se os surdos tinham alguma dúvida e, muito menos, a qualidade da interpretação. Em determinado momento, a professora passou a fazer perguntas oralmente, dirigidas aos alunos ouvintes. Enquanto isso, o intérprete ainda explicava o assunto, utilizando-se, agora, do quadro para se fazer compreender melhor. Depois de um tempo, o intérprete se ausentou da sala. Isso fez com que a professora, que tirava as dúvidas dos ouvintes, se virasse para o surdo e começasse a falar com ele oralmente (vale ressaltar que os surdos desta sala não eram oralizados). Quando o intérprete retornou à sala, os surdos passaram a tirar as dúvidas com o mesmo, que náo as levou à professora, respondendo de acordo com seus conhecimentos.

\section{Situação 4}

\section{Aula de Inglês: assunto - "Possessive Case"}

A professora entrou em sala, deu avisos, escreveu o conteúdo de sua aula no quadro, depois explicou, enquanto os surdos ainda estavam copiando. Ela não olhava para o local onde os surdos estavam. Sua aula era voltada exclusivamente aos ouvintes. Ela era indiferente à presença dos surdos e mesmo a do intérprete. Terminou sua aula e foi embora sem, em momento algum, ter se voltado ao intérprete ou aos surdos.

A partir da análise dessas situaçôes, foi possível encontrar indícios de ausência de propostas educativas culturalmente vinculadas, que pudessem contribuir para fortalecer as formas de elaboração e expressão dos surdos, corroborando com Santos e Campos (2013, p.17), ao dizerem: "A cultura tradicional e hegemônica dos ouvintes tem sido uma cultura de exclusão para os surdos, uma cultura que tem ignorado as múltiplas narrativas surdas e a história dos surdos".

Essas autoras argumentam que a inclusão, ao estabelecer a educação de todas as pessoas no mesmo espaço, tem contribuído para o uso da mesma didática e metodologia. Isso tem imposto restriçóes aos surdos, em decorrência da falta de diálogo 
com os professores, flagrante nas situações apresentadas, as quais dificultam o surgimento de outras características dentro das peculiaridades viso-gestuais, que pudessem determinar componentes dialetais diferentes, em consonância com as condiçôes sócio -econômicas, geográficas e subjetivas de cada indivíduo surdo. Tais restriçôes se originam no meio familiar, fundamental para que o desenvolvimento se dê naturalmente, pelo fato de a grande maioria dos surdos ser pertencente a famílias de ouvintes; e são agravadas no meio social, dentre eles a escola regular, onde existe um reduzido espectro de possibilidades comunicativas, como foi possível levantar nessas situaçôes.

Assim, acreditamos que, para tornar brasileiros de fato também os cidadãos surdos, é fundamental que sejam viabilizados ambientes de interação real dos surdos com a Cultura Surda. Assim como Klein e Lunardi (2006), entendemos que cultura surda e cultura ouvinte não se encontram em posiçôes opostas. Para elas, "[...] os processos de hibridação nos exigem o registro e análise das relaçôes de poder envolvidas em "fios que se mesclam", constituindo tramas. o poder não se constitui em relaçóes verticais: as bipolaridades se esvaem" (p.19).

Nesse sentido, a Língua de Sinais é fundamental para o estabelecimento da Cultura Surda, porque a língua constitui a nossa pátria, como diz Caetano Veloso ${ }^{1}$ “[...] E deixe os Portugais morrerem à míngua, minha pátria é minha língua [...]". Sendo assim, podemos inferir que a pátria dos surdos não se constitui da mesma forma que a da maioria dos brasileiros, haja vista que sua situação é mais esdrúxula que a de muitos estrangeiros em pátrias alheias. Afinal, não há estrangeirismo que faça estranha sua própria família. A pátria brasileira dos surdos, embora esteja em relação mais ou menos profícua, não possui as mesmas fronteiras que a dos ouvintes, porque sua fronteira é imaterial. A pátria existe onde estiver viva a Língua de Sinais, onde houver surdos interagindo de forma natural.

Por isso, é tâo importante proporcionar ambientes educacionais que não se restrinjam à comunicação surdo-intérprete de Língua de Sinais, mas que de oportunidade de uma comunicação fluente, viva e natural, entre os colegas, o professor e os demais componentes da comunidade escolar. A partir daí, é possível que se enxergue os surdos, percebendo como os mesmos apreendem e organizam o mundo, o que os aproxima e os distancia entre si e de outros grupos, mas, essencialmente, o que pode fazer de sua diferença uma possibilidade de desenvolvimento cognitivo, afetivo, social enfim. Esse é o modo de se considerar a diferença surda, como critério para uma educação de fato. Sem ele, pode-se até vislumbrar alguma aquisição de informaçôes, mas será mais uma maneira alienante, dentre as várias existentes, que a escola promove.

A valorização da Língua de Sinais é uma questão essencial não só como um sistema de códigos, que comunicam idéias. A Língua de Sinais, como qualquer outra língua, precisa ser vetor de desenvolvimento humano. Portanto, sobretudo nos anos iniciais de escolarização, o seu uso é fundamental para os surdos, porque integra um sistema de relaçóes, de contatos, contribuindo para formação de conceitos, de subjetividades. Ela deve estar imbricada a uma prática pedagógica que seja culturalmente engajada, que enxergue para além da informação, sendo também construtora de concepçôes e de visốes de mundo. 
Diante desses princípios, devemos inserir as questôes específicas à Cultura Surda em reflexôes mais amplas. Mesmo percebendo o avanço conceitual existente desde quando se colocava como objetivo maior do ensino especial a integraçâo dos ditos deficientes na sociedade, até os últimos anos, quando se tem defendido a inclusão, é preciso analisar a questão com cautela. A colocação das pessoas especiais em escolas regulares, baseadas na Declaração de Salamanca (UNESCO, 1994), tem provocado interpretaçôes e práticas diferenciadas em diversas localidades, porque traz, em seu conteúdo, diretrizes que não condizem com as práticas historicamente construídas na instituição escolar.

As situaçôes apresentadas mostram claramente que a escola proclamada pela declaração, a escola ideal, está distante de ser concretizada em seus aspectos pedagógicos. A escola real, como mostram os dados, mantém suas estratégias conservadoras e excludentes, servindo de ancoradouro aos arranjos e concepçóes políticas mais amplas. Embora a Declaraçáo tenha sido um marco que colocou na agenda mundial a inclusão, considerando sua abrangência, e que detalhou propostas sobre a necessidade de uma preparação das escolas comuns no que concerne a espaço físico, corpo docente, material didático, etc. Entendemos que o texto legal é inócuo se não for produto das reflexóes dos protagonistas do processo educacional. Ao contrário disso, a inclusão não passa de mais um mecanismo do ideário global capitalista e neoliberal, que, por meio de uma aura de solidariedade e humanismo, de cidadania e respeito aos direitos humanos, professa a aceitação, para controlar e manter as desigualdades.

As práticas expostas mostram que a educação inclusiva, inserida no âmbito geral das políticas brasileiras para educação, tem servido apenas para compor uma visão global de educação, e justificar o subsídio de organismos internacionais (Banco Mundial, UNESCO, ONU), que intervêm nestas políticas (SHIROMA, MORAES, EVANGELISTA, 2000), atribuindo a elas o poderoso papel de ser instrumento para a concretização das ações acordadas em diferentes documentos oficiais.

No Brasil, vários documentos adotam esses princípios, entre eles a proposta encaminhada pelo MEC da Proposta Curricular Nacional- PCN (BRASIL, 1997), a partir da incorporação do tema transversal Pluralidade Cultural, nas políticas curriculares. A partir dos PCNs, o MEC elaborou, em 1999, um documento intitulado "Adaptaçóes Curriculares - Estratégias para a Educação de Alunos com Necessidades Educacionais Especiais” (BRASIL, 1998), baseando-se no pressuposto de que as adaptaçóes curriculares podem atender às necessidades particulares de aprendizagem dos alunos.

Por serem tomados como acréscimos às concepçóes educacionais existentes, essas iniciativas passam a instituir o discurso de solidariedade e da tolerância, reforçando a existência de sub-culturas. Não há movimentos pedagógicos consistentes que busquem apontar caminhos de superaçáo efetiva para a exclusão subliminar, que ainda assola o ensino regular (DORZIAT, 2001). As situaçóes apresentadas neste estudo mostram como as diferenças são contempladas: como acessório, que dá sentido a uma política de educação para todos só no ingresso nas escolas regulares. 
A inclusão passa a fazer parte, assim, de um discurso oficial, apenas como meio de agregar valor às práticas já existentes, sendo tratada principalmente a partir da noção de diversidade cultural, que tem seu significado presente no discurso da UNESCO, como uma "multiplicidade de formas pelas quais as culturas dos grupos e sociedades encontram sua expressão" (UNESCO, 2005, p. 6).

De acordo com Garcia (2008), ao longo do documento a ênfase está nas possibilidades humanas pela expressão de suas variadas formas identificadas à cultura e nas perspectivas de intercâmbio de diferentes grupos. O que náo está explicitado no texto, mas subentendido, segundo ela, é a perspectiva de cultura como mercadoria e de diversidade cultural como meio de sobrevivência de grupos minoritários numa economia de mercado. Essa noção de diversidade defende sociedades plurais, mas administradas por grupos hegemônicos que são criadores de consensos e estabelecem quem faz ou não parte do grupo. Tais estratégias políticas de participação de diferentes grupos sociais têm a intenção de gerar uma sensação de maior igualdade, mas, na verdade, contribuem para manter a desigualdade econômica na medida em que reduz a crítica sobre ela (GARCIA, 2008). Trata-se, portanto, de uma estratégia de controle das diferenças, de maneira hierarquizada, sob a égide de uma economia de poder global.

\title{
Considerações finais: a educação de surdos sob o princípio da diferença
}

Diante do quadro apresentado de ausência de envolvimento com as diferenças, especificamente as das pessoas surdas, concordamos com Deleuze (2000), quando afirma que é preciso alterar a pedagogia tradicional, mas sem confundir a diferença com o oposto. A opção por uma política das diferenças na educação passa por um questionamento radical da educação, para poder apreendê-la na sua essência, como uma questão que é da escola, mas que envolve para além dela. Nesse sentido, a educação de surdos em tempos de inclusão envolve aspectos individuais, que contemplem a Língua de Sinais, bem como, como afirma Campello (2007),

\begin{abstract}
a organizaçáo de uma pedagogia visual, que contemple a elaboração do currículo, didática, disciplina, estratégia, contação de história ou estória, jogos educativos, envolvimento da cultura artística, cultura visual, desenvolvimento da criatividade plástica, visual e infantil das artes visuais, utilização da linguagem de Sign Writing (escrita de sinais) na informática, recursos visuais, sua pedagogia crítica e suas ferramentas e práticas, concepção do mundo através da subjetividade e objetividade com as "experiências visuais". (CAMPELLO apud PERLIN, 2007, p. 129).
\end{abstract}

Mas envolve, também, aspectos gerais como o engendramento das políticas globalizadoras e neoliberais.

Vistas nesse emaranhado de discursos e ações, as situações apresentadas mostraram que é preciso, primeiro, superar visōes compartimentalizadas dos fenômenos que veem a surdez como se fizesse parte de uma característica individual a ser com- 
batida, e não como uma criação social, que justifica a seletividade e o preconceito; e, depois, acreditar que a aceitação da lógica da diferença requer o abandono de ideias cristalizadas e o entendimento sobre a complexidade que envolve cada situação educacional.

\section{Referências}

BAUMANN, R. (Org.). O Brasil e a economia global. Rio de Janeiro: Campus, 1996.

BRASIL. Lei de diretrizes e bases da educaçáo - LDB. Brasília: MEC, 1996. SEF, 1997.

Parâmetros curriculares nacionais: introdução aos parâmetros curriculares nacionais. Brasília: MEC/

Parâmetros curriculares nacionais: adaptaçóes curriculares. Brasília: MEC/SEF/SEESP, 1998.

CAMPELLO, A. R. S. Pedagogia visual/sinal na educaçáo dos surdos. In: QUADROS, R. M; PERLIN, G. (Orgs.). Estudos Surdos II. Petrópolis: Arara Azul, 2007. p. 100-131.

CASTELLS, M. Os novos paradigmas tecnológicos e suas implicaçóes econômicas e sociais. Brasília: Fundação Alexandre de Gusmão, 1995.

CORAZZA, S. M. Pistas em repentes: pela reinvenção artística da educação, da infância e da docência. In: GALLO, S.; SOUZA, R. M. (Orgs.). Educação e preconceito: ensaios sobre poder e resistência. Campinas: Alínea, 2004. p. 179-187.

Diferença e repetiçáo. Lisboa: Relógio d'Água, 2000.

DORZIAT, A. Bilinguismo e surdez: para além de uma visão linguística e metodológica. In: SKLIAR, C. (Org.). Atualidade da educaçáo bilíngue para surdos. v. 1. Porto Alegre: Mediação, 1999. p. 27-40.

Educação de surdos no ensino regular: inclusão ou segregação? Cadernos de Educaçáo Especial, Santa Maria, Universidade Federal de Santa Maria, v. 2, n. 24, p. 77-85, jun. 2004.

FORQUIN, J. F. Escola e cultura: as bases sociais e epistemológicas do conhecimento escolar. Porto Alegre: Artes Médicas, 1993.

GARCIA, R. M. C. Políticas inclusivas na educação: do global ao local. In: BAPTISTA, C. R.; CAIADO, K. R. M.; JESUS, D. M. (Orgs.). Educaçáo especial: diálogo e pluralidade. Porto Alegre: Mediação, 2008. p. 11-24.

KLEIN, M.; LUNARDI, M. L. Surdez: um território de fronteiras. Educaçáo Temática Digital. Campinas, v. 7, n. 2., p. 14-23, 2006.

LÜDKE, M.; ANDRÉ, M. E. D. A. Pesquisa em educação: abordagens qualitativas. 9. ed. São Paulo: EPU, 2005.

SACKS, O. Vendo vozes: uma jornada pelo mundo dos surdos. Rio de Janeiro: Imago, 1990.

SANTOS, L. F.; CAMPOS, M. L. I. L. Educaçẫo especial e educação bilíngue para surdos: as contradiçōes da inclusão. In: ALBRES, N. A.; NEVES, S. L. G. (Orgs.). Libras em estudo: política educacional. São Paulo: Feneis, 2013. p.13-38.

SANTOS, B. S. A globalizaçáo e as ciências sociais. 3. ed. São Paulo: Cortez, 2005.

SHIROMA, E. O.; MORAES, M. C. M.; EVANGELISTA, O. Política educacional. Rio de Janeiro: DP\&A, 2000 .

SKLIAR, C. (Org.). Abordagens sócio-antropológicas em educação especial. Educação e exclusão: abordagens sócio-antropológicas em educação especial. Porto Alegre: Mediação, 1997. p. 7-20.

UNESCO. Declaraçáo de Salamanca e linha de açáo sobre necessidades educativas especiais. Brasília: CORDE, 1994.

Convençáo sobre a proteçáo e promoçáo da diversidade das expressóes culturais. Brasília: MEC, 


\section{Nota}

${ }^{1}$ Música "Línguas”, composta por Caetano Veloso.

\section{Correspondência}

Ana Dorziat - Universidade Federal da Paraíba, Centro de Educação - Campus I, Departamento de Habilitaçốes Pedagógicas. Cidade Universitária, Castelo Branco, CEP: 58059-900 - João Pessoa, Paraíba - Brasil.

E-mail: ana_dorziat@hotmail.com

Recebido em 24 de julho de 2014

Aprovado em 14 de outubro de 2014 